\title{
The Mental Health Impact of the Coronavirus Disease-19 Pandemic on Resident Doctors at M. Jamil Hospital Padang, Indonesia
}

\author{
Yaslinda Yaunin ${ }^{1}$, Rini Gusya liza ${ }^{1}$, Satya Wydya Yenny ${ }^{2 *}$, Dwi Sabtika Julia² \\ ${ }^{1}$ Departement of Psychiatry, Faculty of Medicine, Andalas University, Padang, Indonesia; ${ }^{2}$ Department of Dermato-Venereology, \\ Faculty of Medicine, Andalas University, Padang, Indonesia
}

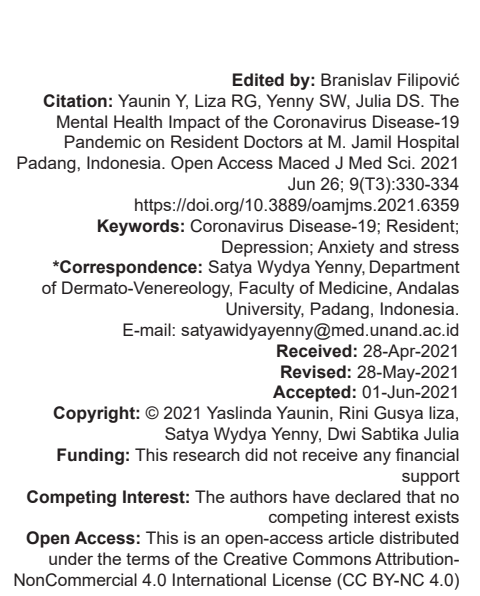

\section{Introduction}

Since the first cluster of the coronavirus disease 2019 (COVID-19) cases was found in Wuhan, China at the end of December 2019, reporting of cases has widely spread over in the first few months of 2020 [1]. The virus was originally known as The Severe Acute Respiratory Syndrome-Coronavirus-2 (SARSCoV-2) and recognized as a pandemic by the World Health Organization (WHO) on March 11, 2020. As of 3 May 2020, a total of 3,349,786 cases and 238, 628 deaths have been reported worldwide. Of all the worst scenarios faced by the healthcare workers while on duty tending to COVID-19 patients, nosocomial spread and infection are the major concerns [2]

Both medical staff and non-medical related healthcare workforce are all under physical and psychological duress in the face of the COVID-19 pandemic. As suggested by previous studies, when there was a spike in SARS and bird flu (H1N1) cases, it required different reactions and work experience patterns among health workers. They are obliged to work with new work systems, health protocols, and personal protective equipment (PPE) in tending to patients with mild to severe illness and with half colleagues who have fallen ill [3]. Other potentially important at-risk publicfacing workers include emergency services personnel (e.g., police and fire), hospital cleaners, those in the hospitality industry and public transport and taxi drivers, to name but a few [1].

Chew et al. organized a research in five major hospital involved in the care for COVID-19 patients, in Singapore and India within the period of February 19April 17, 2020. The research was conducted by using the "Depression Anxiety Stress Scales (DASS-21)" and the "Impact of Events Scale-Revised (IES-R)" to identify symptoms of depression, anxiety, stress and post-traumatic stress disorder (PTSD) were evaluated. Healthcare workers included in the research are doctors, nurses, administrators, and instrument operators. The results show that $8.11 \%$ of the doctors and nurses involved suffer from depression, $10.8 \%$ of the experience anxiety, $6.4 \%$ are under stress, and $5.7 \%$ struggle with PTSD. As for the administrators and operators, the analysis reveal $10.8 \%$ of them involved suffer from depression, $20.7 \%$ experience anxiety, $6.9 \%$ are under stress and $10.9 \%$ struggle with PTSD [4], [5]. 
Lu et al. conducted a study on healthcare workers from Fujian Province Hospital, China. The Hamilton Anxiety Scale (HAMA) and Hamilton Depression Scale (HAMD) questionnaires were distributed on 25-26 February 2020. The results obtained show that the medical staff is more afraid, anxious, and depressed than the administrative staff. Medical staff working in the Pulmonology/Respiratory department, emergency unit, intensive care units (ICU), and infectious diseases are twice as anxious and depressed as non-clinical staff as they are in direct contact with coronavirus patients [6].

Research conducted by Pathirathna et al. examines how Australia, Singapore, Sri Lanka, and the UK take action and select priority areas of work as issued by the $\mathrm{WHO}$ in the event of dealing with the first two stages of disease transmission scenarios. There are differences in the implementation approach and priority areas for strategic work as well as differences in the availability and sustainable plan movement in the economic sector. They conclude that health and political authorities around the world need strong mechanisms for the preparedness, response, and coordination in handling infectious diseases of a similar nature. The incidence of one case should be enough to encourage measures are taken to prevent uncontrolled transmission and initiate action and priority areas of work as stated in the $\mathrm{WHO}$ interim guidelines [7].

Al - Khani et al. ran a study on 206 medical students to see the relationship between sleep quality, mental health, and academic scores in Saudi Arabia in March 2018. The prevalence of poor sleep was $63.2 \%$; it was higher among students who were physically inactive and had more screen time. Poor sleepers demonstrated higher academic performance than sufficient sleepers $(p=0.04)$. The prevalence of depression, anxiety, and stress was $42 \%, 53 \%$, and $31 \%$, respectively. Sleep quality was significantly associated with depression $(p=0.03)$, anxiety $(p=0.007)$, and stress $(p=0.01)[8]$.

\section{Methods}

\section{Research setting and population}

This research was conducted from July 13 to July 31,2020 . The inclusion criteria for participants in this study are residents at the Faculty of Medicine, University of Andalas, Padang, West Sumatra, Indonesia. At the time of the research, they are in training and on duty at Dr. M. Djamil Padang and are willing to participate in the research by signing the informed consent prepared by the authors. Residents who are on leave or outstationed during the study period are excluded from the study. Written informed consent is obtained from all participants. This research is approved by the Research
Ethics Committee of the Faculty of Medicine, Andalas University, Padang, West Sumatra.

\section{Screening system through questionnaires}

The participants filled in an online questionnaire uploaded in the Google form application. It consists of several questions covering the components of basic demographic characteristics such as gender, marital status, with or without children, place of duty, and contact history with patients who were confirmed positive for COVID-19.

Upon completion of filling in the online questionnaire, the graphs and data summary will automatically be formulated.

\section{Depression, anxiety and stress level measurement questionnaire}

To assess the level of anxiety, depression and stress in the study participants during the COVID-19 pandemic, we use the DASS-42, which consists of 42 questions: 14 questions related to the depression scale, 14 questions related to the anxiety scale, and 14 questions related to the stress scale. Each participant will mark the most suitable answers to describe their condition during the COVID-19 pandemic. Each question is scored ranging from 0 to 3 with $0=$ none/never, $1=$ sometimes, $2=$ often, and $3=$ almost every time. The scores of the 42 questions will be added up to become 1 (one) global score with the assessment indicators according to Table 1 .

Table 1: Scoring Indicator of DASS*

\begin{tabular}{llll}
\hline Level & Depression & Anxiety & Stress \\
\hline Normal & $0-9$ & $0-7$ & $0-14$ \\
Mild-moderate & $10-20$ & $8-14$ & $15-25$ \\
Severe-crushing & $>21$ & $>15$ & $>26$ \\
\hline "DASS: The Depression, Anxiety and Stress Scale & &
\end{tabular}

\section{Study outcomes}

This study provides the characteristics description of the resident at the Dr. M Djamil Hospital who carry out the care for the COVID-19 patients. It assesses the preparation and implementation level during the COVID-19 outbreak, it later gauges the level of depression, anxiety and stress experienced by the participants related to the support services to the care of COVID-19 patients they perform.

\section{Results}

\section{Participants}

Out of the 494 total residents who are in training and posted at M Djamil Hospital, 448 (90.7\%) 
Table 2: Participants basic characteristics $(n=448)$

\begin{tabular}{|c|c|}
\hline Characteristic & $\mathrm{n}(\%)$ \\
\hline \multicolumn{2}{|l|}{ Gender } \\
\hline Male & $220(49.1)$ \\
\hline Female & $228(50.9)$ \\
\hline \multicolumn{2}{|l|}{ Marital Status } \\
\hline Married & $362(80.8)$ \\
\hline Single & $81(18.1)$ \\
\hline Divorced & $5(1.1)$ \\
\hline \multicolumn{2}{|l|}{ Children (Married participants) } \\
\hline With children & $291(78)$ \\
\hline Without children & $82(22)$ \\
\hline \multicolumn{2}{|l|}{ Specialization } \\
\hline Pediatrics & $41(9.2)$ \\
\hline Internal Medicine & $75(16.7)$ \\
\hline Surgery & $56(12.5)$ \\
\hline Obstetrics and Gynecology & $63(14.1)$ \\
\hline Dermatology and Venereology & $23(5.1)$ \\
\hline Ophthalmology & $33(7.4)$ \\
\hline Otolaryngology & $28(6.3)$ \\
\hline Heart and Vascular & $31(6.9)$ \\
\hline Pulmonology and Respiratory & $37(8.3)$ \\
\hline Neurology & $17(3.8)$ \\
\hline Clinical Pathology & $29(6.5)$ \\
\hline Pathology Anatomy & $15(3.3)$ \\
\hline \multicolumn{2}{|l|}{ Ongoing Supervision } \\
\hline High Supervision (Red Badge) & $5(1.1)$ \\
\hline Moderate-High Supervision (Yellow Badge) & $131(29.2)$ \\
\hline Moderate Supervision (Green Badge) & $169(37.7)$ \\
\hline Low Supervision (Blue Badge) & $143(31.9)$ \\
\hline \multicolumn{2}{|l|}{ Station during COVID-19 pandemic } \\
\hline Outpatient clinic & $285(63.6)$ \\
\hline Ward & $351(78.3)$ \\
\hline Triage & $100(22.3)$ \\
\hline Emergency Unit & $355(79.2)$ \\
\hline Operating theater & $141(31.5)$ \\
\hline Isolation ward & $176(39.3)$ \\
\hline CVCU & $6(1.4)$ \\
\hline Laboratory & $20(4.5)$ \\
\hline \multicolumn{2}{|c|}{ Contact history with patient who is confirmed positive for COVID-19 } \\
\hline Yes & $184(41.1)$ \\
\hline No & $264(58.9)$ \\
\hline
\end{tabular}

agree to participate in this research. There are 228 female residents $(50.9 \%) ; 60$ residents $(13.4 \%)$ are 31 years old; 362 residents (80.8\%) are married, and 291 residents $(78 \%)$ are married with children (Table 2). The largest contingent goes to Internal Medicine 75 residents $(16.7 \%)$ and followed by OBGYN 63 residents $(14.1 \%)$ and surgery with 56 residents $(12.5 \%)$. As many as 169 residents (37.7\%) are under moderate supervision (Green Badge).

During the COVID-19 pandemic, 355 residents $(79.2 \%)$ are mostly assigned to the ER, followed by 351 residents $(78.3 \%)$ manning the wards. A total of 184 residents $(41.1 \%)$ have contact history with COVID-19 positive patients, while 264 residents $(59.2 \%)$ have none. Data are shown in Table 2.

\section{Psychological outcomes}

DASS-42 is used as tool in this study to assess the levels of anxiety, depression and stress experienced by the study participants during the COVID-19 pandemic. Based on the DASS-42 scoring system, it is found that 58 residents $(12.9 \%)$ suffer from mild-moderate anxiety level and 12 residents $(2.7 \%)$ toil with severe-crushing level. Meanwhile, there are 57 residents $(12.7 \%)$ experiencing mildmoderate depression and 19 residents (4.2\%)
Table 3: Prevalence of participants' anxiety, depression and stress level

\begin{tabular}{lll}
\hline Psychological outcomes & Frequency & Percentage (\%) \\
\hline Depression & & \\
$\quad$ Normal & 371 & 82.8 \\
Mild -Moderate & 57 & 12.7 \\
$\quad$ Severe-Crushing & 19 & 4.2 \\
Anxiety & & \\
$\quad$ Normal & 377 & 84.2 \\
$\quad$ Mild -Moderate & 58 & 12.9 \\
$\quad$ Severe-Crushing & 12 & 2.7 \\
Stress & & \\
$\quad$ Normal & 338 & 75.4 \\
$\quad$ Mild-Moderate & 89 & 19.9 \\
$\quad$ Severe-crushing & 20 & 4.5 \\
\hline
\end{tabular}

labor under severe-crushing, 89 residents (19.9\%) experience mild-moderate stress, and 20 residents $(4.5 \%)$ struggle with severe-crushing stress. Data are shown in Table 3.

\section{Discussion}

The main challenge for healthcare workers during the COVID-19 pandemic is caring for positively infected patients, as it poses a serious risk for workers in ICU as they have to be in constant contact with infected patients for long periods of time. Widespread infections and deaths among healthcare workers have been previously reported for MERS and SARS and currently for the COVID-19; this has caused social and mental distress on them. On the course of SARS dan MERS outbreaks, health workers reported concerns about themselves and the health of their families and described their painful experiences manifested in fear, anxiety, and even social prejudice and stigma [9], [10].

Moreover, it has been proven that health workers tend to continue to work without rest and later undergo burnout, mental stress, anxiety, and symptoms of depression, including during the epidemic mitigation [11]. Hong completed a study to show that PTSD is quite common among survivors of infectious diseases [12]. The majority of participants in this study are women, with 228 female residents $(50.9 \%)$ take part in filling in the questionnaire. The biggest age bracket is 31 years old as 60 residents $(13.4 \%)$ are in that age and most participants (362 residents/80.8\%) are married with 291 residents $(78 \%)$ are married with children. Walton's research finds that stress differences are related to gender and whether or not children are involved. Women indeed show higher stress levels than men. In addition to that, healthcare workers who have children reported lower levels of perceived stress than their childless counterparts.

Another study during the COVID-19 pandemic discovers that healthcare workers with children at home observe a reduced level of pressure at work [13]. Having children may represent a protective factor against perceived stress, enabling healthcare workers 
to focus on positive aspects of their lives [14]. It can be argued that children would act as a "break" from taxing working hours, the demands of work when dealing with patients and fatigue [15].

A study by Babore (2020) finds no association between perceived stress and marital status stress; furthermore, there is no difference in stress between those who have a partner and those who do not. These findings are inconsistent with previous epidemics studies that highlight higher depressive symptoms and psychological distress among single hospital staff [15]. On the other hand, Li et al. (2020) particularly argue that marital status is a risk factor for insomnia for the medical staff population when they are at home, Tan et al. (2020) show that marital status is associated with the severity of psychiatric symptoms in the general population and Doshi et al. (2020) find that married people have a higher risk of having a greater fear of COVID-19 in the general Indian population [16], [17], [18].

The coronavirus pandemic is the most challenging threat to human health over the past decades and has profoundly affected medical community. In such a public health crisis, health workers are demanded to try harder to extend their working hours. To make things worse, the perpetual use of PPE) adds to physical exhaustion and mental stress in healthcare workers [19]. In general, the emerging outbreak contributes to a universal atmosphere of fear that needs to be deliberated psychologically through comprehensive research activities in order to apprehend the likely impacts on individual mental health and productivity, which in turn will reduce the impact on health workers, particularly the front-liners who ward off at all fronts. At time like this, providing health workers with adequate support by acknowledging their conditions and the solutions presented to tackle their problems, increasing their awareness of current situation, cheering for them, and recognizing their interests tends to strengthen them in the fight against the disease [13].

This study finds that 57 residents suffer from mild-moderate depression $(12.7 \%)$ and 19 residents $(4.2 \%)$ struggle with severe-very severe depression. The other 58 residents $(12.9 \%)$ experience mildmoderate anxiety, while 12 residents (2.7\%) labor under severe-very severe anxiety. Mild-moderate stress affects 89 residents (19.9\%) and severe-very severe stress impact 20 residents $(4.5 \%)$. This is in line with Liu's research in 2020 on mental health in COVID-19 time and the results suggest that $45 \%$ health workers exhibit severe symptoms of anxiety. Amongst medical staff members treating COVID-19 patients, anxiety levels affect their psychological state by increasing stress levels and decreasing sleep quality and selfeffectiveness [9].

Bukhari et al. perform research concerning anxiety associated with contact and transmission of MERS-CoV on Saudi Arabian healthcare workers working during the outbreak. It discloses that $7.8-20.5 \%$ of the respondents are very worried about contracting MERS-CoV after more than 4 weeks; $12.2-21 \%$ of the reported sample are very concerned about passing the infection on to family members or friends. One month after the end of the H1N1 pandemic, Goulia et al. find that $56.7 \%$ of their research participants remain to display a fairly high level of anxiety about the disease [20]. 1-2 years after the SARS outbreak, 30.4\% healthcare workers who are in direct contact with infected patients still suffer from high levels of emotional exhaustion Bai et al. state that there are significantly higher rates of emotional exhaustion among SARS health workers compared with non-health workers [21].

In this study, 184 (41.1\%) healthcare workers have a contact history with positive COVID-19 patients. The exposure level to infection appears to influence psychological outcomes. Studies show that healthcare workers assigned in units with a high risk of infection present more severe mental health outcomes compared to healthcare workers in units with low infection risk. Direct contact with an affected patient is a risk factor that has a significant impact on mental health [18].

Kang et al. conclude problems faced by health workers responding to the COVID-19 pandemic are high risk of infection, inadequate protection from contamination, overwork, frustration, discrimination, isolation, patients with negative emotions, lack of contact with their families, and fatigue." The evidence reviewed here, both linked to the COVID-19 pandemic and previous epidemic/ pandemic outbreaks, clearly confirm that facing such problems come with psychological impact on healthcare workers responding to outbreaks [22].

\section{Conclusion}

Most residents participated in this study. The majority of residents are women and are married with children. During the COVID-19 Pandemic, the majority of residents are mostly stationed at the emergency room and are in contact with COVID-19 positive patients. The results show that residents experience depression, anxiety and stress from mild to severe stages. The limitation of this study is that it does not differentiate the level of depression, anxiety and stress based on the work station and work shifts.

\section{References}

1. Sim MR. The COVID-19 pandemic: Major risks to healthcare and other workers on the front line. Occup Environ Med. 2020;77(5):281-2. https://doi.org/10.1136/oemed-2020-106567 PMid:32238444 
2. lannone P, Castellini G, Coclite D, Napoletano A, Fauci AJ, lacorossi $\mathrm{L}$, et al. The need of health policy perspective to protect Healthcare workers during COVID-19 pandemic. A GRADE rapid review on the N95 respirators effectiveness. PLoS One. 2020;15(6):e0234025. https://doi.org/10.1371/ journal.pone.0234025

\section{PMid:32492045}

3. Walton M, Murray E, Christian MD. Mental health care for medical staff and affiliated healthcare workers during the COVID-19 pandemic. Eur Heart J Acute Cardiovasc Care. 2020;9(3):241-7. https://doi.org/10.1177/2048872620922795 PMid:32342698

4. Chew NW, Lee GK, Tan BY, Jing M, Goh Y, Ngiam NJ, et al. A multinational, multicentre study on the psychological outcomes and associated physical symptoms amongst healthcare workers during COVID-19 outbreak. Brain Behav Immun. 2020;88:55965. https://doi.org/10.1016/j.bbi.2020.04.049

PMid:32330593

5. Tan BY, Chew NW, Lee GK, Jing M, Goh Y, Yeo LL. Psychological impact of the COVID-19 pandemic on Health Care Workers in Singapore. 2020;173(4):317-20.

PMid:32251513

6. Lu W, Wang H, Lin Y, Li L. Psychological status of medical workforce during the COVID-19 pandemic: A cross-sectional study. Psychiatry Res. 2020;288:112936. https://doi. org/10.1016/j.psychres.2020.112936

PMid:32276196

7. Pathirathna R, Adikari PS, de Alwis S. Perceived satisfaction of A\&E staff on the level of integration of patient care operations with emergency ambulance service, Sri Lanka. Recent Adv Biol Med. 2020;6(3):1-5. https://doi.org/10.18639/rabm.2020.1128039

8. Al Khami AM, Sarhandi MI, Zaghloul MS, Ewid M, Saquib N. A cross sectional survey on sleep quality, mental health and academic performance among medical students in Saudi Arabia. BMC Res Notes. 2019;12(1):665. https://doi.org/10.1186/ s13104-019-4713-2

PMid:31639038

9. Liu S, Yang L, Zhang C, Xiang YT, Liu Z, Hu S, et al. Online mental health services in China during the COVID-19 outbreak. Lancet Psychiatry. 2020;7(4):e17-8. https://doi.org/10.1016/ s2215-0366(20)30077-8 PMid:32085841

10. Almutairi AF, Adlan AA, Balkhy HH, Abbas OA, Clark AM. It feels like I'm the dirtiest person in the world: Exploring the experiences of healthcare providers who survived MERS-CoV in Saudi Arabia. J Infect Public Health. 2018;11:187-91. https:// doi.org/10.1016/j.jiph.2017.06.011

11. Lancee WJ, Maunder RG, Goldbloom DS. Coauthors for the Impact of SARS Study. Prevalence of psychiatric disorders among Toronto hospital workers 1 to 2 years after the SARS outbreak. Psychiatr Serv. 2008;59(1):91-5. https://doi. org/10.1176/ps.2008.59.1.91 PMid:18182545

12. Hong $X$, Currier GW, Zhao $X$, Jiang $Y$, Zhou W, Wei J. Posttraumatic stress disorder in convalescent severe acute respiratory syndrome patients: A 4-year follow-up study. Gen Hosp Psychiatry. 2009;31(6):546-54. https://doi.org/10.1016/j. genhosppsych.2009.06.008

PMid:19892213

13. Chen Q, Liang M, Li Y, Guo J, Fei D, Wang L, et al. Mental health care for medical staff in China during the COVID-19 outbreak. Lancet Psychiatry. 2020;7(4):e15-6. https://doi.org/10.1016/ s2215-0366(20)30078-x PMid:32085839

14. Talaee N, Varahram M, Jamaati H, Salimi A, Attarchi M, Dizaji $\mathrm{MK}$, et al. Stress and burnout in health care workers during COVID-19 pandemic: Validation of a questionnaire. Z Gesundh Wiss. 2020:1-6. https://doi.org/10.1007/s10389-020-01313-z

15. Babore A, Lombardi L, Viceconti ML, Pignataro S, Marino V, Crudele M, et al. Psychological effects of the COVID-2019 pandemic: Perceived stress and coping strategies among healthcare professionals. Psychiatry Res. 2020;293:113366. https://doi.org/10.1016/j.psychres.2020.113366 PMid:32798932

16. Li X, Yu H, Bian G, Hu Z, Liu X, Zhou Q, Yu C, et al. Prevalence, risk factors, and clinical correlates of insomnia in volunteer and at home medical staff during the COVID-19. Brain Behav Immun. 2020;87:140-1. https://doi.org/10.1016/j.bbi.2020.05.008 PMid:32380272

17. Tan W, Hao F, McIntyre RS, Jiang L, Jiang X, Zhang L, et al. Is returning to work during the COVID-19 pandemic stressful? A study on immediate mental health status and psychoneuroimmunity prevention measures of Chinese workforce. Brain Behav Immun. 2020;87:84-92. https://doi. org/10.1016/j.bbi.2020.04.055

PMid:32335200

18. Doshi D, Karunakar P, Sukhabogi JR, Prasanna JS, Mahajan SV. Assessing Coronavirus fear in Indian population using the fear of COVID-19 scale. Int J Ment Health Addict. 2020:1-9. https:// doi.org/10.1007/s11469-020-00332-x

19. Al-Rabiaah A, Temsah MH, Al-Eyadhy AA, Hasan GM, Al-Zamil F, Al-Subaie $\mathrm{S}$, et al. Middle east respiratory syndromeCorona virus (MERS-CoV) associated stress among medical students at a university teaching hospital in Saudi Arabia. J Infect Public Health. 2020;13(5):687-91. https://doi.org/10.1016/j. jiph.2020.01.005 PMid:32001194

20. Bukhari EE, Temsah MH, Aleyadhy AA, Alrabiaa AA, Alhboob AA, Jamal AA, et al. Middle east respiratory syndrome Coronavirus (MERS-CoV) outbreak perceptions of risk and stress evaluation in nurses. J Infect Dev Ctries. 2016;10(8):845-50. https://doi. org/10.3855/jidc.6925

PMid:27580330

21. Bai YM, Lin CC, Lin CY, Chen JY, Chue CM, Chou P. Survey of stress reactions among health care workers involved with the SARS outbreak. Psychiatr Serv. 2004;55(9):1055-7. https://doi. org/10.1176/appi.ps.55.9.1055 PMid: 15345768

22. Kang L, Li Y, Hu S, Chen M, Yang C, Yang BX, et al. The mental health of medical workers in Wuhan, China dealing with the 2019 novel Coronavirus. Lancet Psychiatry. 2020;7(3):e14. https://doi.org/10.1016/s2215-0366(20)30047-x PMid:32035030 